\title{
Quality Circles in Hospital: An Exploratory Study
}

\author{
Vivin George ${ }^{1}$, Vijay Kumar Tadia ${ }^{2}$ \\ ${ }^{1}$ Asst. Professor, MIMS College of Allied Health Sciences, MIMS Academy, Aster Healthcare, \\ ${ }^{1}$ Senior Resident Administrator, Department of Hospital Administration, AIIMS, New Delhi, India
}

\begin{abstract}
Introduction: Quality circle (QC) consists of people working in a common work area, coming together voluntarily to identify, analyze and solve various quality related problems within their area.

Methodology: The exploratory study was done in a hospital in India that was part of large public sector organisation that ran the program of QC across its institutions and also in its non-core areas like the hospitals.

Primary data was collected from the staff working in the hospital that was part of quality circles.

Results: Most of the QC members reported an improvement in terms of the Job satisfaction and accomplishment that was measured on the 6 parameters. The perception of the Non-members about the general organizational climate was on the lower side in comparison to the members ofthe QCs. The members of the QC seemed to fare better than the Non- members.

Discussion and Conclusion: If the top and middle management develop faith and conviction in the efficacy of the QC program, then rolling this out is not an issue at all. Most of the members were appreciative of the fact that program of this kind was great learning experience. There was a unanimous agreement on the fact that this activity should continue and be extended to the whole of the organization in the whole country.

The findings suggested that the employees saw positive changes after becoming part of QCs in regard to their personal growth and they also perceived positive changes in certain important organizational aspects which helped them to function effectively.
\end{abstract}

The organizational climate seemed to have improved with QC as reflected in job satisfaction and sense of accomplishment between QC members and non-Members.

Keywords: Quality Circle, Work Satisfaction, Organizational Climate.

\section{Introduction}

Quality circle (QC) consists of people working in a common work area, coming together voluntarily to identify,analyze and solve various quality related problems within their area. This approach is unique because it revolves around the concept that the people

\footnotetext{
Corresponding Author:

Vijay Kumar Tadia

Senior Resident Administrator, Department of Hospital

Administration, AIIMS, New Delhi, India

e-mail: vijaytadia@gmail.com
}

who are actually doing the work identify, analyze and find solution to their work area and present it to the management. ${ }^{1}$ The whole crux lies in building the capacities of the people rather than offering them with solutions to every day to day problem. ${ }^{2}$

The concept of Quality circles (QCs) has its origin in Japan and was primarily used to get the Japanese economy on its feet after the II World war. The commander of the occupied Forces in Japan was instrumental in bringing Dr. Demings who along with Dr. J. Juran was responsible for the introduction of the total quality control concept in Japan. ${ }^{3}$ Quality circles came to India when BHEL (Bharath Heavy Electricals Ltd) Hyderabad established the first circle. ${ }^{4}$ 
A hospital setup where the safety of the staff and patients is important, the application of these concepts can prove beneficial as in the case of other industries. A QC team identified three specific targets for them to achieve to ensure a safe work environment for its workers. After having identified the causes of the problems, the team members were able to analyze the problems, generate alternative solutions, and eventually implement the best solutions. Consequently, the members were able to achieve all their targets. ${ }^{5}$ The implementation of the concept is not that rosy if it is accompanied by the intent of just cutting cost or saving on certain areas and forgets it main emphasis of empowering the employees then the circle is bound to fail. Organizational issues at the background stage; circle-formation issues at the implementation stage; and operational issues at the operating/running stage of Quality Circle implementation, are the three main key areas of the problems which generally limit the success of the Quality Circle. ${ }^{6}$

To assess the effects of a Quality Circles program within a dynamic organizational environment, it has been strongly recommended that the collection of both outcome and process type data within the context of a rigorous experimental design. Taken together, outcome and process measures can shed a great deal of insight into a more complete understanding of the effects of the QC process on individual and organizational functioning. ${ }^{7}$

\section{Methodology}

The exploratory study was done in a hospital in India that was part of large public sector organisation that ran the program of QC across its institutions and also in its non-core areas like the hospitals.

Primary data was collected from the staff working in the hospital that was part of quality circles. The sample frame was the members who participated in quality circle process.

\section{The study samples were drawn from the organization as:}

1. Top Management-Senior manager and above.

2. Middle Management-Below senior manager to frontline supervisor.

3. Workers who were part of the Quality circle activities (Members).

4. Workers who had not joined QCs (Non-members).
Convenience Sampling was used to select the managers. The workers who had not joined Quality Circles from those areas where the QC was functioning were included as Non-QC members. The QC members were selected from almost all the operational areas support services as well as clinical services.

The total number 33 QC groups were included for the study of which 18 were from the clinical and the rest were from the non-clinical areas. Same number of members and non-members were taken from the same areas.

The QC members in the study were mostly comparable in age and length of service. Their educational and technical backgrounds were similar except in some cases. In cases of non-members too, there was not much deviation in case of age or qualifications except in some cases.

\section{fold: \\ The variables included in the study were two}

1. Opinions, attitudes and reactions of the top and middle level management, QC members andnonmembers

2. Variables related to quality of worklife

Data on these variables was collected through questionnaires and interviews.

For collection of the data, top and middle management personnel were approached personally, interview schedules were used for the members and questionnaires were distributed to non-members.

\section{Results}

The data was analyzed with regard to the benefit to the member of quality circle and to the organization. Comparison analysis of clinical staff and non- clinical staff and members of quality circles with non-members was done.

Top Management: Most of the top management personnel had an opportunity to understand the QC concept and they believed in the efficacy of quality circles. Many of the top management personnel stated that launch of QCs was justified and it could be extended to other areas also. The interest of top management was indirectly gauzed from the number of presentations they had attended. Most of them had attended 4-5 meetings per year. 
Middle Management: Most of the middle level managers working in the areas where QC was functioning were aware of the concepts and its activities.
The responses of middle level managers are discussed below (Figure 1).

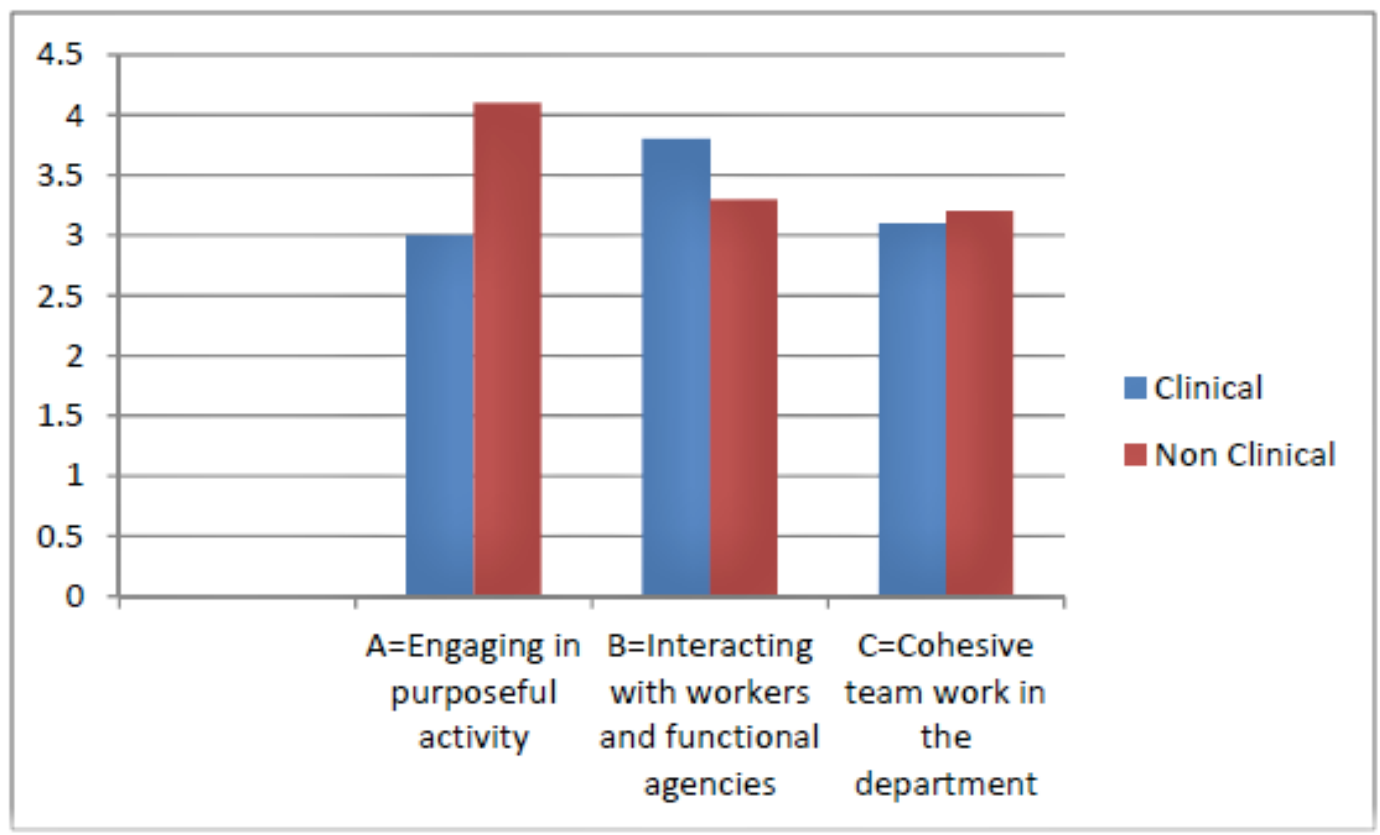

Figure 1: Influence of QC activities on organizational issues as perceived by middle managers (Mean)

Majority of the respondents said that they had perceived positive changes in the attitudes of the members of the QC towards their work. When asked about their perception of the employees engaging in purposeful activities most of them believed that they did it to some extent. The Non-clinical managers felt that the QC was improving the time spent on purposeful activities. There was not much difference among clinical and non-clinical managers with regard to the perception about the interaction with other agencies and team work in the department. The middle managers are not very convinced that the time and effort that goes into the QC activities as worthwhile. It was observed that a larger proportion of the respondents seldom sought help from the QC groups.

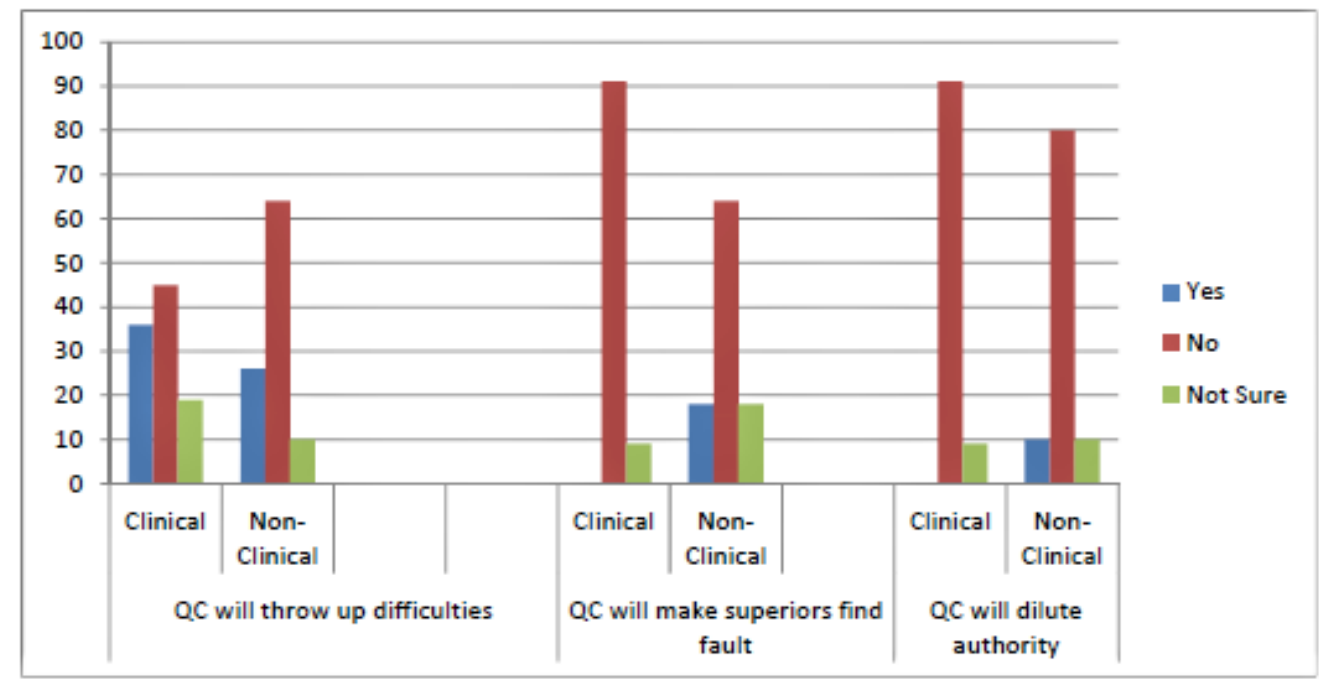

Figure 2: Percentage of Middle Managers reporting about the effect of QCs on their work role 
Most of the middle managers were not apprehensive of losing their authority (Figure 2) as a result of QC. A small percentage of respondents felt that because of QC activities, their difficulties would show up while a few were unsure.

The Clinical mangers were confident that the QC would neither make their superiors find fault with them, nor would it dilute their authority which was the apprehension to a lesser extent of the non-clinical managers. In the case of clinical managers, most of their authority was statutory and most of the functions they performed were exclusive unlike the Non-Clinical counterparts.

Most of the respondents (96\%) accorded recognition to the good work done by QC members. A high percentage $(75 \%)$ of managers also gave recognition by the way of attending the QC meetings. $84 \%$ of the non-clinical managers said that they offered voluntary assistance to circle members and $64 \%$ of the clinical managers said that they adopted this method as a means to recognize the QC effort.

The clinical managers were of the view that the greatest impact of the QCs was appreciable in aspects like, removal of barrier between management and workers and improved morale and communication. The non-clinical mangers were also of the same view except in certain areas where they thought that removal of the barriers can be a problematic thing. Most of the middle managers expressed that the approach of voluntary discussions and problem solving would be helpful among the executives too.

\section{Non Members:}

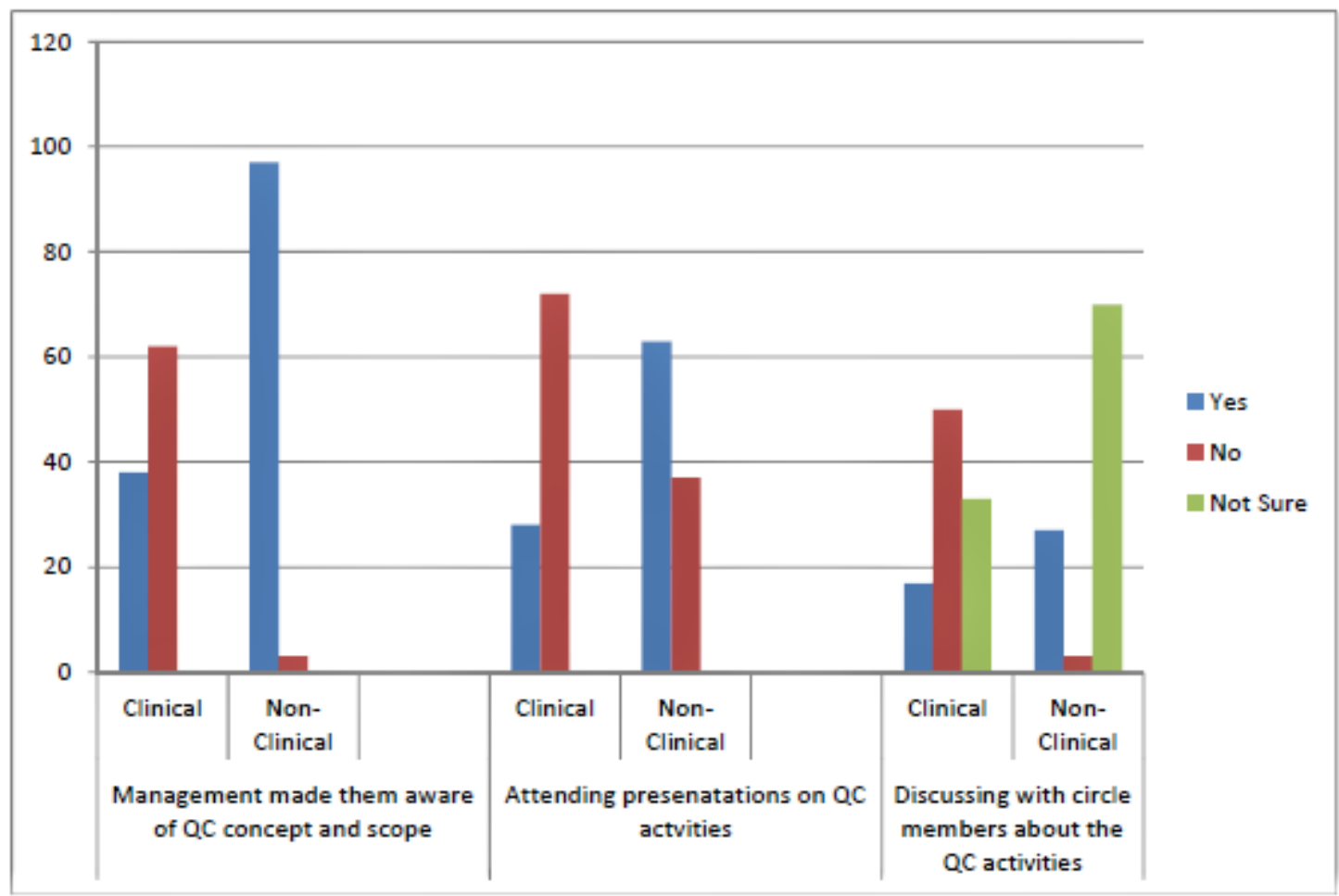

Figure 3: Percentage of non-members from the Clinical and non-clinical areas reporting on the way they got information about Quality Circles.

Most of the non-members from the non- clinical areas $(97 \%)$ stated that the management had made them aware of the concepts of QC and its scope. A larger proportion of the non-members from the non-clinical areas had attended some form of presentation program on the QC activities when compared to their counterparts in the clinical areas. The discussion with circle members about the QC activities was more prevalent in the NonClinical areas than in the Clinical areas. To the question, "if there is a circle in your area, would you like to 
join?", a large majority of the non-members responded in affirmative.

\section{Quality circle Members:}

\section{Formation of QC groups:}

- $63 \%$ of the respondents said that they became members of the QC voluntarily and almost all of them reported that they had fully understood the concept of QCs.

- $22 \%$ reported that they were asked by the departmental heads to be come members

- $15 \%$ said that they were nominated.

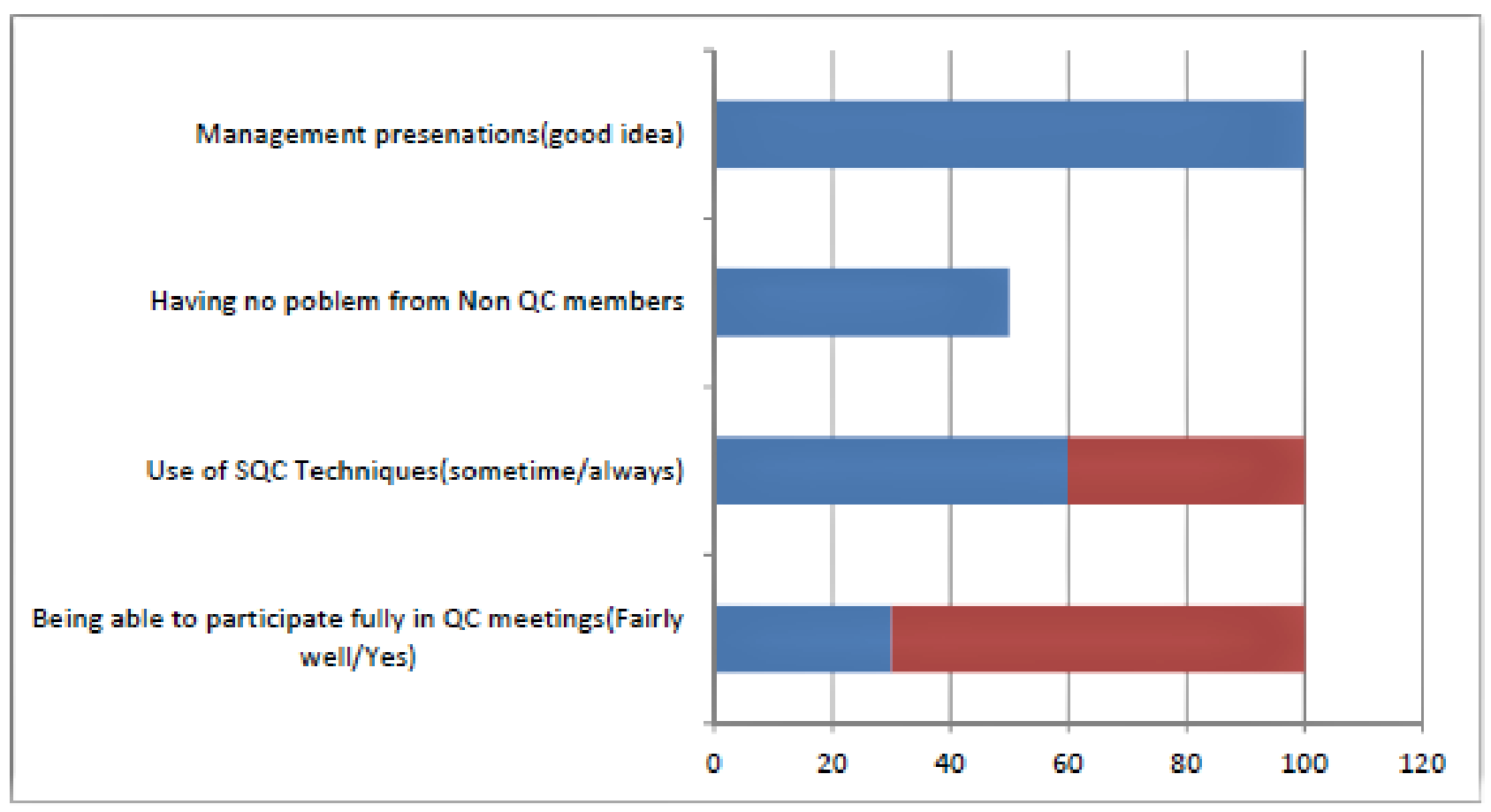

Figure 4. Percentage response of QC members towards various aspects relating to QC operations

- All the QC members were able to participate in the meetings freely.

- All the members felt that the management presentations should be continued.

\section{Selection of QC members:}

- Over $50 \%$ of the respondents in both the clinical and the non-clinical areas stated that it was by consensus.

The respondents said that the selection of the leaders was by

- Nomination (21\%),

- Seniority (16\%)

- Elections $(6 \%)$
Adequacy of training: More than $50 \%$ of the respondents said that it was not adequate.

\section{Operational Aspects:}

- Most of the respondents stated that the frequency of meetings was weekly and that they attended the meetings often.

- Most of the QC members were able to participate in the meetings freely.

- All the members felt that the management presentations should be continued. 
Assessment of Quality of Work Life:

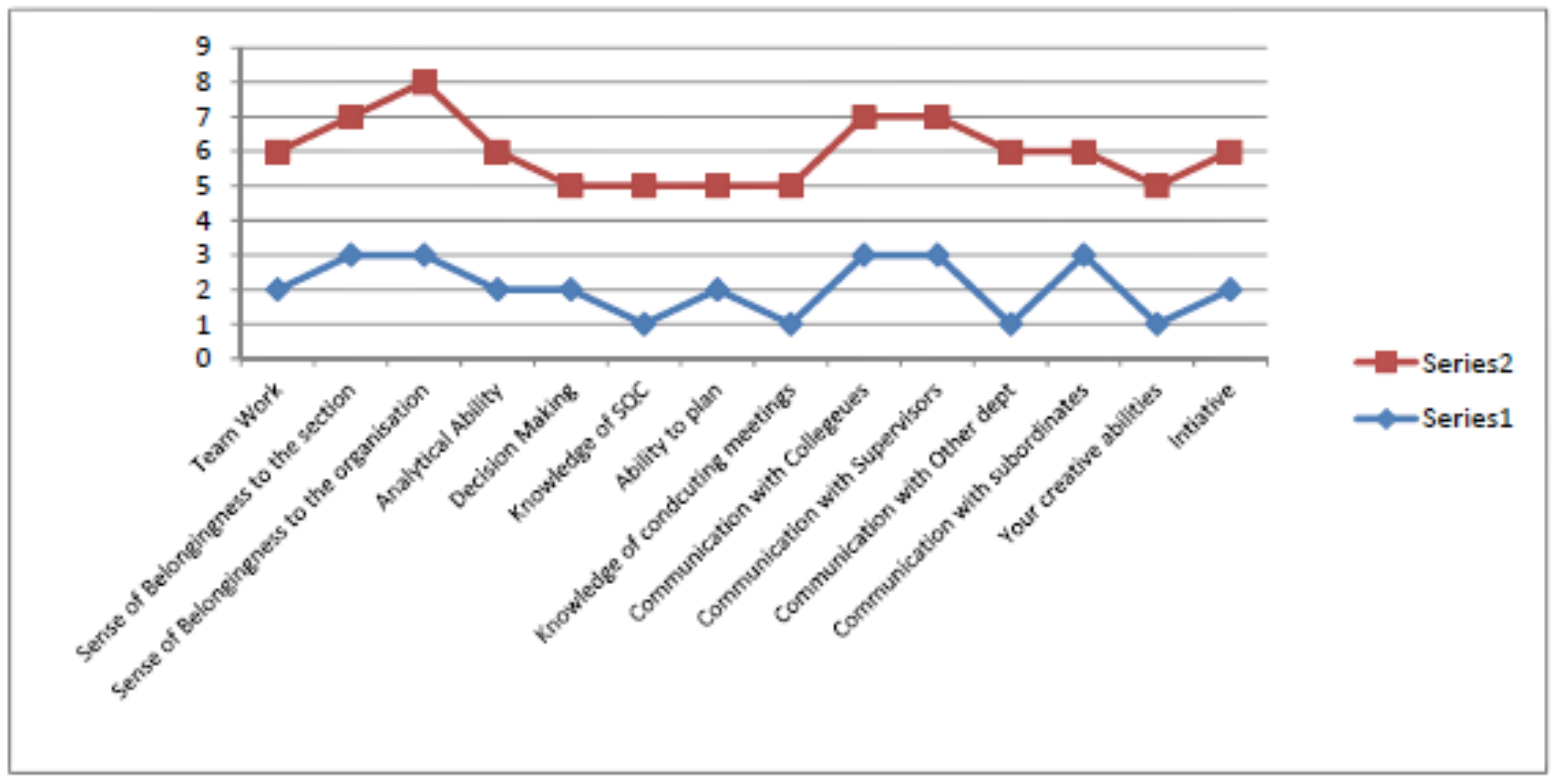

Figure 5: Assessment of changes as perceived by QC members on work and organizational climate

- The self-reported changes: The members rated themselves as experiencing positive changes before and after joining quality circles.

- Rating about changes in work and organizational aspects was also positive side.

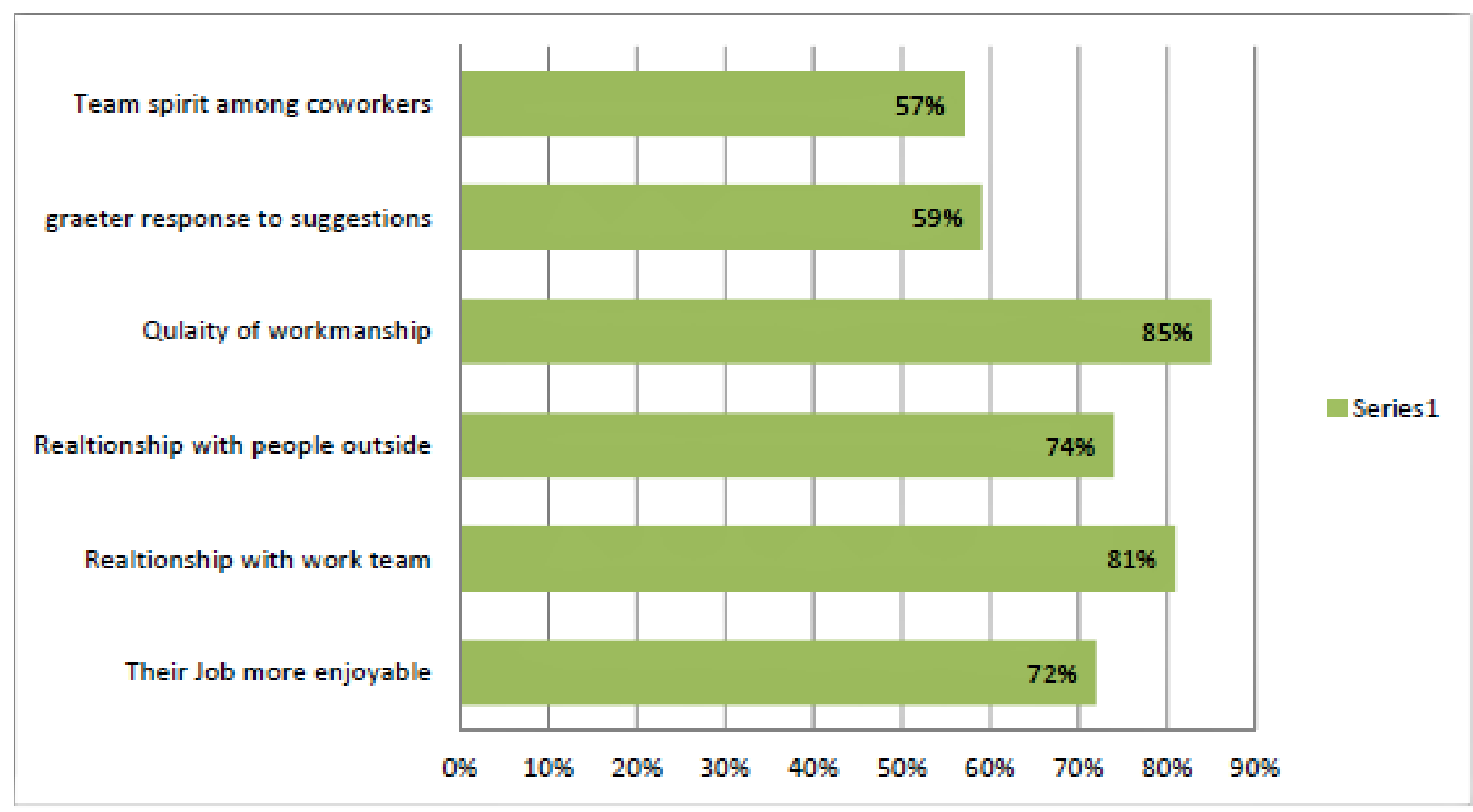

Figure 6: Percentage of QC members reporting about changes due to QC activities on various work-related matters. 
Most of the QC members reported an improvement in terms of the Job satisfaction and accomplishment that was measured on the 6 parameters (Figure . 6).Though it was not be a very holistic way of measuring job satisfaction but it did give an indication into what things were like.

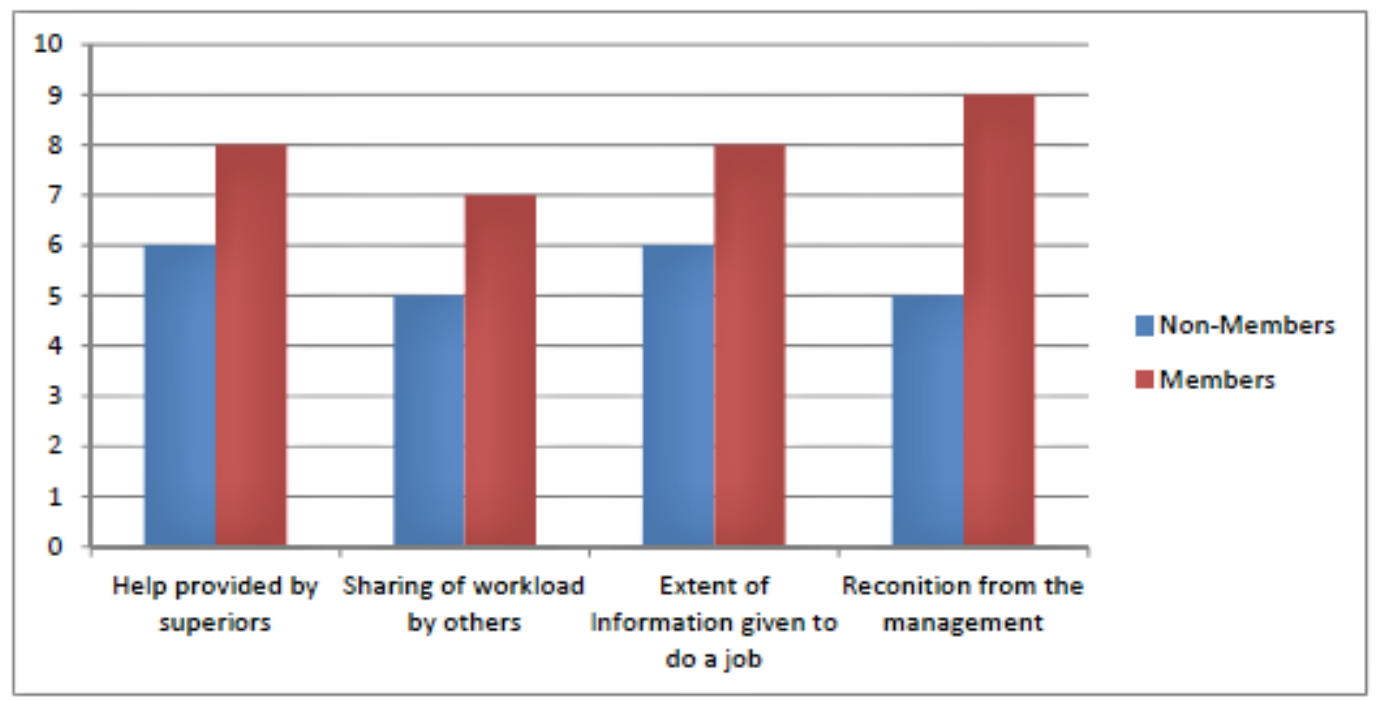

Figure 7: Assessment of factors relating to organizational climate by members and nonmembers

The perception of the Non-members about the general organizational climate was on the lower side in comparison to the members of the QCs. The members of the QC seemed to fare better than the Non- members.

This is an important aspect with regard to the work life quality assessment as the feeling of alienation i.e. that of powerlessness and that their destiny was not controlled by someone else was less in case of members of the Qc in comparison to the non-Members.

\section{Discussion and Conclusion}

If the top and middle management develop faith and conviction in the efficacy of the QC program, then rolling this out is not an issue at all. Sometimes it requires a little bit of push from the side of the top management to reach out to those areas that are reluctant to take part in the QC process.

The middle managers were highly skeptical about the QC to start off with slowly embraced the whole idea when they saw positive changes in the form improved organizational work culture and environment started to appear.

Most of the non-members most of them were aware of the QC activities in the work area and many of them wanted to join it. There were only few pockets of resistance especially from people who were a little older because they thought that QC might include things like statistics that they might not be able to master and hence can make themselves vulnerable to the younger group who might actually grasp these things better.

Most of the members were appreciative of the fact that program of this kind was great learning experience. There was a unanimous agreement on the fact that this activity should continue and be extended to the whole of the organization in the whole country.

The effectiveness of the QC program can be gauzed from the fact that the alienation among the members decreased. On the other hand, the non-members felt powerlessness and alienated. The QC shall be practiced by following systematic approach and based on the philosophies of QC rather than only for tangible gains.

Most of the non-members didn't have any problem in principle with the concept of QC and they were waiting for the appropriate opportunity to be in QC themselves. From this it can be deduce that most of the Non-members are potential members. It is an onus on the organizations to identify as much avenues as possible to explore this opportunity to help perpetuate the Idea of QCs. 
Majority of the members had reported that they joined the QCs voluntarily which was a good sign, some of them have reported that they were asked by the departmental heads or were nominated. In most of the cases the leaders were selected by consensus. This points toward a healthy trend in maintenance of the QCs. It is also important to note that almost all the members expressed their satisfaction about the help received from their managers.

All QC members gave importance to factors like training, management support, recognition, and enthusiastic facilitators for the success of the program. The least significant for success of the QC program according to them was the monetary rewards.

The findings suggest that the employees saw positive changes after becoming part of QCs in regard to their personal growth and they also perceived positive changes in certain important organizational aspects which helped them to function effectively.

The organizational climate seemed to have improved with QC as reflected in job satisfaction and sense of accomplishment between QC members and non-Members.

The members belonging to the QC group enjoyed a high quality of work life. For a QC program to succeed the organizational leadership plays a particularly important role.

\section{Conflict of Interest: Nil}

\section{Source (s) of Support: Nil}

Ethical Clearance: The study was conducted as a dissertation for Master in Hospital Administration.

\section{References}

1. UNIDO. An e-learning Manual for Implementing Total Quality Management Volume 2 [Internet]. 2007 [cited 2020 Oct 6]. Available from: https:// www.unido.org/sites/default/files/2007-11/71783 TCB_No.13.Road_Map_to_Quality_Vol.2_0.pdf

2. S K Dey. Genesis of Quality Circle with a Case Study. J Inst Eng. 1997;78(May):24.

3. Ganapathy K, Narayana V, Subramaniam B. Quality circle concept and implementation. Quality Circle Forum of India. 1994.

4. Srinivasan A V. Quality Circle Movement in India: A Status Report. ASCI J Manag [Internet]. 1991 [cited 2020 Oct 6];21(1). Available from: https:// www.asci.org.in/journal/Vol.21(1991-92)/v21_1_ sri.htm

5. Salaheldin SI, Zain M. How quality control circles enhance work safety: A case study. TQM Mag. 2007;19(3):229-44.

6. Prakas Majumdar J, Murali Manohar B. How to make Quality Circle a success in manufacturing industries. Asian J Qual. 2011 Nov 29;12(3):24453.

7. Mento AJ, Steel RP. Conducting Quality Circles Research: Toward a Comprehensive Perspective. Public Product Rev [Internet]. 1985 Oct 6;9(1):3548. Available from: http://www.jstor.org/ stable/3379923 